\title{
Percutaneous closure of congenital coronary artery fistulae in $\mathbf{5}$ children: A single center experience
}

\author{
Shiv Kumar Yadav, Qi-jian Yi \\ Heart Center, Children's Hospital of Chongqing Medical University, Chongqing, China
}

\section{A B S T R A C T}

Background and Aim: Coronary artery fistulae (CAF) are rare anomalies. In this study, we have done percutaneous closure of CAF in children with three different devices; ventricle septal defect (VSD) occluder, patent ductus arterious (PDA) occluder and Cook coil. Materials and Methods: We retrospectively reviewed all patients, admitted to our heart center inpatient department between September 2004 and April 2013, that had a percutaneous closure of CAF in our center, and evaluated outcomes of patients with CAF treated with cardiac catheterization. Results: A total of five patients ( 3 females) ranged in age from 7 months to 10 years with congenital CAF underwent percutaneous closure. The fistulae had origins from right coronary artery (RCA) and from left coronary artery (LCA) in 3 cases and 2 cases respectively. One RCA drained to right atrium and rest four drained to right ventricle. All 5 cases had a continuous murmur. During closure, 2 fistulae closed with VSD occluder, 2 with PDA occluder \& 1 with Cook coil. Percutaneous closure was successfully achieved in all the 5 patients. Follow-up studies showed that there was complete abolition without recanalization. No deaths occurred. Conclusion: Percutaneous closure of congenital CAF is very safe and effective in children with less complication and shorter hospital stay.
Access this article online

Website:

http://nepjol.info/index.php/AJMS

DOI: $10.3126 / a j m s . v 6 i 4.11786$

\section{INTRODUCTION}

Congenital coronary artery fistula (CAF) is an uncommon form of congenital heart disease, ${ }^{1}$ although outflow tract obstruction is one of the underlying etiological factors of ventriculo-coronary connections in ventricular hypoplastic diseases, especially in the presence of an intact ventricular septum. $^{2}$ Angiographic studies have revealed that the incidence of CAF ranges from 0.3 to $0.8 \% .^{3}$ However, most patients with such anomalies are asymptomatic, early treatment is recommended to prevent complications such as congestive heart failure, pulmonary hypertension, myocardial ischemia or infarction, fistula rupture with cardiac tamponade, and infective endocarditis. ${ }^{4,5}$ The first successful transcatheter closure of a coronary artery fistula was reported by Reidy et al. in 1983 using a detachable balloon. ${ }^{6}$

\section{MATERIALS AND METHOD}

We have collected the pediatric percutaneous closure databases from Children's Hospital of Chongqing Medical University, Chongqing, P. R. China, to identify all patients with CAF who underwent to percutaneous closure from September 2004 to April 2013. All cases that had percutaneous closure for CAF with 3 different devices were studied. Medical records from all clinical details, electrocardiograms, chest X-ray, percutaneous closure data, and pre \& post occlusion echocardiography parameters were analyzed. Records and angiograms from the occlusion procedures were studied to characterize hemodynamics, CAF anatomy, percutaneous closure technique, devices placement, procedure complications and CAF occlusion.

Address for Correspondence:

Qi-jian Yi, MD, Ph.D. Heart Center, Children's Hospital of Chongqing Medical University, No.136,

Zhongshan Second Road, Yuzhong District,

Chongqing, P. R. China, 400014.

Phone: 0086-23-63624344; E-mail: qjyi2003@126.com.

(C) Copyright AJMS 


\section{RESULTS}

\section{Study Patients}

Between September 2004 and April 2013, we prospectively collected data on 5 cases with all available clinical details, cardiac catheterization data and echocardiography parameters had reviewed. All of 5 cases underwent percutaneous closure of a CAF at our institution. Patients we assessed by a standard echocardiographic protocol; all patients underwent transthoracic echocardiography (T'TE). Written and informed consent obtained from all patients' guardians before underwent percutaneous closure.

Out of the 5 cases, there were 3 females and 2 males. Their age ranged between 7 months to 10 years 10 months (average aged 4.13 year). Table 1 describes the clinical characteristics of these patients prior to intervention. The most frequent findings were palpitation and continuous murmur, prior to intervention. Of all 5 patients who underwent percutaneous closure were congenital CAF with no any associated congenital anomalies.

\section{Coronary artery fistula characteristics}

The hemodynamic and angiographic characteristics of CAF closed with 3 different devices are described in Table 2. Of the 5 CAF in which 3 different devices: VSD occluder, PDA occluder \& detachable Cook coil were deployed. In 3 cases, fistulas were originating from right coronary artery (RCA) and in 2 cases from left coronary artery (LCA). Drainage sites included the right ventricle (RV) in 4 patients and right atrium in 1 case Table 2 . None case had found more than one orifice fistula. Table 2 describes the fistula details, device size and procedural data.

\section{Procedure details}

Percutaneous closure of a CAF is performed under general anesthesia. Patients are given heparin $100 \mathrm{IU} / \mathrm{kg}$ body weight intravenously during the femoral venous and arterial accesses. The procedure was performed under fluoroscopy and transthoracic echocardiography (TTE) control. After obtaining the hemodynamic data; aortic root angiography and selective coronary angiography were performed to demonstrate the fistulae anatomical structure, its drainage site, and identify distal coronary branches. CAF closure was attempted percutaneous occlusion in all the cases. VSD occluders were used in 2 cases, PDA occluders in 2 and Cook Coil in 1 case. Among the 5 patients, 4 approached the fistula through the antegrade venous approach and closed the fistula with VSD occluders \& PDA occluders while only one through the retrograde arterial route and closed with Cook coil. Selective coronary angiography and aortic angiography was performed just after device deployment. Finally, the correct position was confirmed and the devices were released. Embolization was achieved in all patients.

\section{CAF occlusion with COOK Coil}

Percutaneous closure was attempted by a retrograde approach via femoral artery access with a 5 French $(\mathrm{Fr})$ sheath, and using a standard microcoil embolization technique as previously described. ${ }^{7,8}$ Angiographic views allowed adequate visualization of the fistula (Figure- $1 \mathrm{a} \& \mathrm{~b}$ ) in order to determine the appropriate site for device delivery, and the coil size required. A 5Fr 3.50 guide catheter (TERUMO Corp., Tokyo, Japan) was positioned at the left coronary ostium. The delivery catheter, a $2.6 \mathrm{Fr} 150 \mathrm{~cm}$ Excelsior 1018 (144181) microcatheter guide (TERUMO Corp., Tokyo, Japan), was advanced under fluoroscopic guidance over a RADIFOCUS's guide wire (TERUMO Corp., Tokyo, Japan) directly to the distal coronary artery

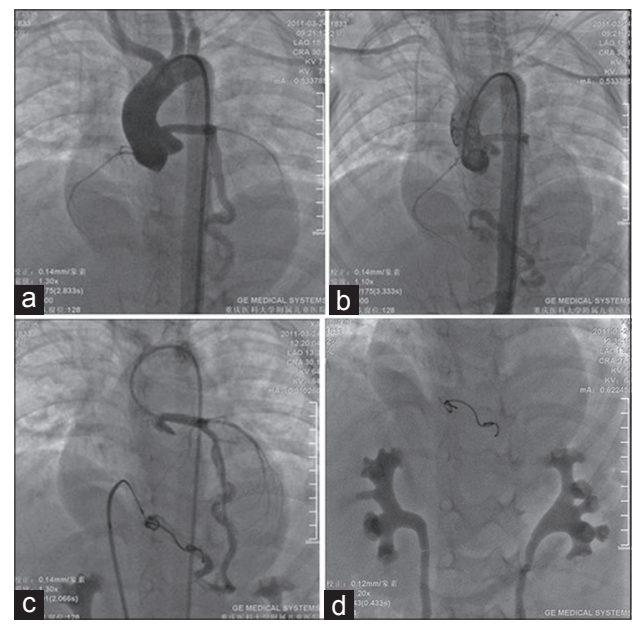

Figure 1: $(a, b)$ The ascending aorta angiography and left coronary artery imaging display, which shows left coronary artery to right ventricle fistula, (c) The ascending aorta angiography is demonstrating satisfactory position of device cook coil, (d) Fluoroscopy shows the complete fistula occlusion with cook coil (Patient No. 3)

\begin{tabular}{|c|c|c|c|c|c|}
\hline $\begin{array}{l}\text { No. of } \\
\text { patient }\end{array}$ & Age & Gender & Major complaints & Murmur & $\begin{array}{l}\text { Associated } \\
\text { Cardiac lesions }\end{array}$ \\
\hline 1 & $5 Y 3 M$ & Female & Palpitation, dyspnea & + & None \\
\hline 2 & $1 \mathrm{Y} 6 \mathrm{M}$ & Female & Palpitation, dyspnea (-) & + & None \\
\hline 3 & $2 Y 4 M$ & Female & Palpitation, dyspnea (-) & + & None \\
\hline 4 & $10 Y 10 M$ & Male & Palpitation, dyspnea (-) & + & None \\
\hline 5 & $7 \mathrm{M}$ & Male & Cough, dyspnea, Palpitation (-) & + & None \\
\hline
\end{tabular}




\begin{tabular}{|c|c|c|c|c|c|}
\hline $\begin{array}{l}\text { No. of } \\
\text { patient }\end{array}$ & $\begin{array}{l}\text { Fistula } \\
\text { type }\end{array}$ & $\begin{array}{l}\text { Occluder } \\
\text { type }\end{array}$ & $\begin{array}{l}\text { Occluder } \\
\text { size }\end{array}$ & Occlusion & $\begin{array}{l}\text { Procedure } \\
\text { time (min) }\end{array}$ \\
\hline 1 & RCA-RV & PDA-occluder & $10-12 \mathrm{~mm}$ & Complete & 130 \\
\hline 2 & RCA-RA & VSD-occluder & $5 \mathrm{~mm}$ & Complete & 90 \\
\hline 3 & LCA-RV & Cook coil & $5 \times 5 \mathrm{~mm}$ & Complete & 230 \\
\hline 4 & RCA-RV & PDA-occluder & $8-10 \mathrm{~mm}$ & Complete & 80 \\
\hline 5 & LCA-RV & VSD-occluder & $6 \mathrm{~mm}$ & Complete & 135 \\
\hline
\end{tabular}

(Note: RCA-RV=Right Coronary Artery to Right Ventricle, RCA-RA=Right Coronary Artery to Right Atrium, LCA-RV=Left Coronary Artery to Right Ventricle, $\mathrm{mm}=$ Millimeter)

(LCX) in order to occlude the drainage orifice and minimize the risk of distal embolization. Hemodynamic parameters were assessed by use of microcatheter at the level of the fistula. The microcatheter was then positioned in the proximal segment of the fistula (vessel diameter at the point was $2.25 \mathrm{~mm}$ ) and a single stainless-steel COOK microcoil (5x5 mm; COOK Sandet-6, Bjaeverskov DENMARK) was deployed and advanced by using a straight 0.038 inch guidewire (Figure 1c). Just after releasing the device, coronary angiography confirmed successful occlusion of the fistula with minimal residual flow from the fistula (Figure 1d). Following the above procedures, coil was implanted. Coronary angiography was repeated to confirm the quality of the occlusion, and heparin (100 U per kg) was given during the procedure. There were no ECG (Electrocardiography) changes noted; no procedural complications occurred and the patient was discharged on the following day. The patient subsequently reported that her earlier clinical symptoms had completely disappeared, and that his recovery had continued uneventfully. We have not found any recurrence on follow up.

\section{CAF occlusion with PDA ocluder}

During the operation, two sheaths were inserted from the right and left femoral arteries and a sheath was inserted from the right femoral vein. From the right and left femoral arteries, a 6Fr JR3.5 guiding catheter (TERUMO Corp., Tokyo, Japan) and a 5Fr pigtail catheter (TERUMO) were inserted separately into the origin of CAF. Selective right coronary angiography showed a tortuous and giant fistula from the RCA to the RV, and the distal part of the CAF was enlarged markedly (Figure 2a). A $260 \mathrm{~cm} 0.889 \mathrm{~mm}$ (0.035') exchange wire (TERUMO) and a 5Fr multipurpose catheter (TERUMO) were inserted along the $6 \mathrm{Fr}$ guiding catheter and passed through the CAF to the RV. Then, the wire was inserted into the RA. The exchange wire was pulled out from the femoral vein by a gooseneck snare (TERUMO), which was inserted from the femoral vein into the RA; then the circuit was established from the femoral artery to the femoral vein. An 8Fr delivery sheath (Lifetech Scientific Inc., China) was inserted into the RA from the femoral vein along the circuit and kissed with a multipurpose catheter in the RA. Further, the long sheath

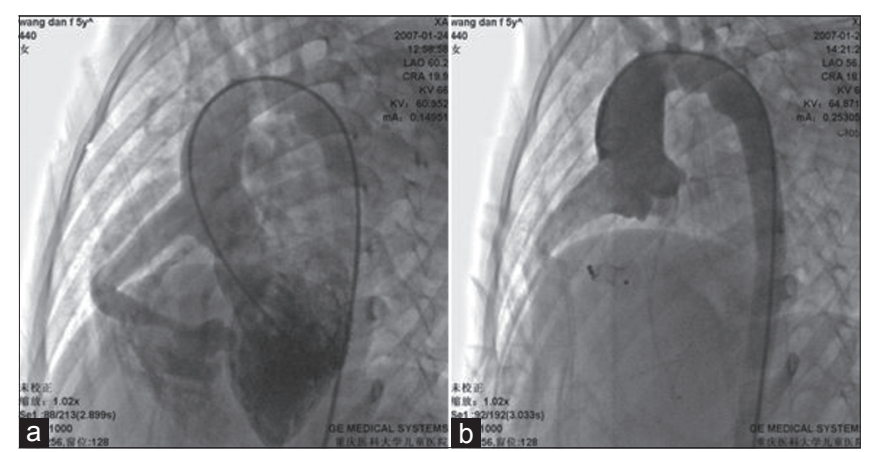

Figure 2: (a) Aortic angiogram shows blood vessels branches and right coronary artery to right ventricle fistula, (b) Ascending aorta angiogram is demonstrating satisfactory position of device and showing complete fistula occlusion with PDA occluder (Patient No. 1)

was inserted into the CAF slowly. After this, the dilator and multipurpose catheter were drawn out, but the exchange wire was kept in the CAF. A native 10/12 mm Patent Duct Arteriosus (PDA) occluder (Lifetech Scientific Inc., China) was inserted to the top of the long sheath for $1^{\text {st }}$ patient ( $4^{\text {th }}$ patient used $8 / 10 \mathrm{~mm}$ ). The long sheath was pulled out slowly, and the occluder was extended at the end of the CAF. When the occluder was successfully deployed in position, the exchange wire was pulled out from the femoral vein, and the occluder successfully closed the CAF without residual shunt (Figure 2B). The patient had no complaints and the ECG was similar to the preoperative one during the 30-minute observation. The RA and RV were normal on Trans-thoracic echocardiography (TTE), and a 12-lead ECG $24 \mathrm{hr}$ postprocedure was unchanged. The patient's heart murmur disappeared. One month, 3 months, 6 months and 12 months later, the above symptoms did not recur.

\section{CAF occlusion with VSD Occluder}

The percutaneous closure procedure had done same as PDA occluder approach but we have chosen VSD occluder according to coronary angiography (CAG), showed the fistula was straight and tubular in shape (Figure 3a). The $2^{\text {nd }}$ patient (RCA to RA) $\& 5^{\text {th }}$ patient (LCA to RV), VSD occluder had used $5 \mathrm{~mm}$ and $6 \mathrm{~mm}$ respectively. Occlusion has been done under fluoroscopy control (Figure 3b \& c). Once the occluder deployed in position, CAG showed the occluder successful occlude CAF without residual shunt (Figure $3 \mathrm{~d}-\mathrm{f}$ ) and the patients had no any complaints during 30 minutes observation. The TTE has not shown any abnormalities and ECG was normal, which might show myocardial infarction (MI). The patient's murmur has disappeared. There was no recurrence of the above symptoms on follow up. The guide wire, pigtail catheter, exchange wire, multipurpose catheter, and gooseneck snare were used from TERUMO Corp., Tokyo, Japan. At same time, VSD occluder and delivery sheath were used from Lifetech Scientific Inc., China. 


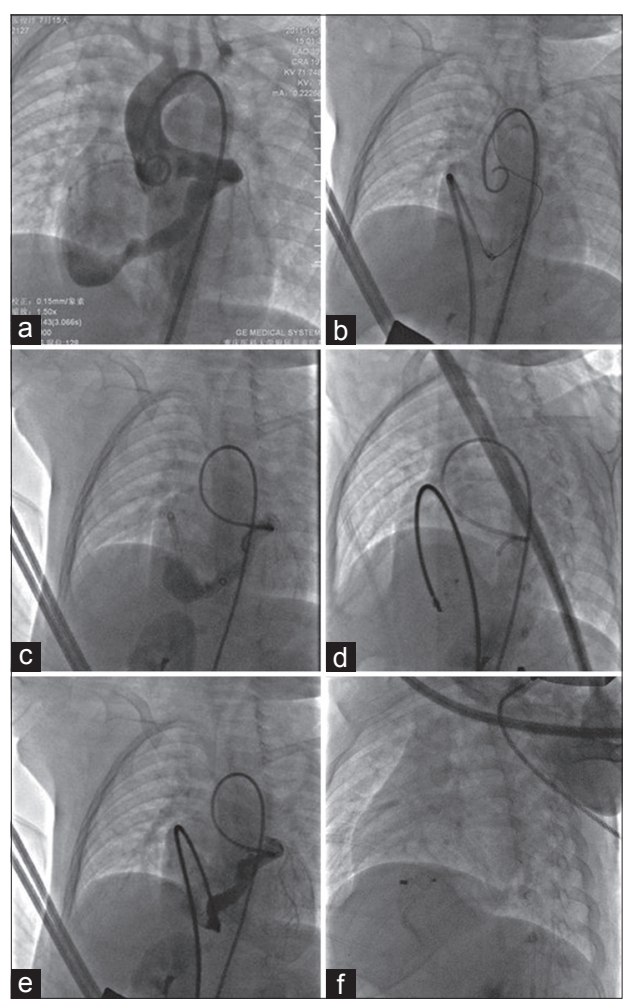

Figure 3: (a) Aortic Angiogram shows blood vessels branches and Leftt coronary artery to right ventricle fistula, (b, c) Fluoroscopy shows the exchange wire through the fistula, the occluder moving toward the fistula respectively, (d) The ascending aorta angiogram showed the occluder placed in position just before releasing. (e) Coronary angiogram is demonstrating position of the occluder without residual shunt, (f) Fluoroscopy shows the complete fistula occlusion with VSD occluder (Patient No. 5)

\section{Follow up details}

Electrocardiography (ECG) and chest X-ray and echocardiogram were performed 24 hours after procedure. Echocardiographic and angiographic control showed complete and permanent occlusion in the 5 patients. All patients who underwent successful CAF percutaneous closure were followed up clinically and by chest X-ray, ECG and echocardiogram at 1, 3, 6 and 12 months in the first year and annually thereafter. On follow-up, none of our patients showed recurrence the above symptoms, recanalization of the fistula with recurrence of shunt, embolization of normal coronary branches, migration of closure devices to the cardiac chambers or great arteries, device fracture, or rupture of the fistula itself. No death occurred during procedure and post closure.

\section{DISCUSSION}

Congenital coronary artery fistula (CAF) is an uncommon form of congenital heart disease and rarely spontaneous closure of the fistula may occur. ${ }^{6}$ Although most patients with CAF are asymptomatic but according to our collected data, our patients had the following manifestations: palpitation, dyspnea and continuous murmur. Transthoracic echocardiography (TTE) and Doppler can diagnose coronary artery fistulae and their drainage sites. ${ }^{9}$ However, Trans-esophageal Echocardiograph (TEE) can identify the precise location of drainage site to aid in planning surgery. ${ }^{10}$ Sometimes, angiography may fail to show the drainage site while TEE would be successful., ${ }^{911}$ Recently, some authors have recommended the TEE for the diagnosis of fistulas because of its better resolution. ${ }^{12}$ During surgical management, Intra-operative TEE is useful for (a) localization of drainage site, (b) identify feeding vessels, (c) document abolition of flow (all without need for cardiopulmonary bypass) and (d) continuous monitoring of ventricular function to detect ischemic effects of ligation. ${ }^{13}$ But in our center, we preferred TTE and Doppler for the diagnosis of congenital CAF. Patients with CAF are having complications such as congestive heart failure, fistula rupture; infective endocarditis, myocardial infarction, aneurysm formation, and death are consequences that can be prevented by early diagnosis. A comprehensive review of congenital CAF in children led to the recommendation of early ligation of these fistulas because of the high incidence of infectious and ischemic complications. ${ }^{14}$

Management of congenital CAF is still controversial due to the variability of CAF clinical and angiography findings with hemodynamic changes. Sometimes small lesions are managed conservatively because small and hemodynamically inconsequential CAFs generally run a benign long-term course and some of them close spontaneously. ${ }^{15}$ It is generally recommended that the lesions should be closed, if patients are having symptoms such as dyspnea, cough and palpitation. There are two treatment options available: percutaneous closure and surgical closure of congenital CAF. Some authors reported that surgical treatment is very effective and safe. ${ }^{5,16-18}$ The first successful surgical closure was reported by Biorck et al. ${ }^{19}$ After that there have been many series published up to 56 cases. Overall, mortality is low $(\sim 1 \%)$; single ligation is common; excision of fistula is rare; and cardiopulmonary bypass is used in approximately one-half of the cases. ${ }^{20,21}$ Reported complications are rare and include arrhythmias, myocardial infarctions, stroke, and ST-/T-wave changes on the electrocardiogram. Approximately a 10\% rate of incomplete closure or recurrence of fistulae is reported in the surgical literature. ${ }^{22}$ However, in the Cheung et al., 2001 series of 41 patients, 21 agreed to undergo followup cardiac catheterization. ${ }^{22}$ Among the 21, 4 (19\%) had residual or recurrent fistulae. They noted that the incidence of recurrence was higher in patients who underwent external plication versus those who had intracardiac closure.

Percutaneous closure of CAF is an alternative to surgical closure. The first successful transcatheter closure of a 
coronary artery fistula was reported by Reidy et al. ${ }^{20}$ using a detachable balloon. The advantages of the transcatheter closure of CAFs are: shorter hospital stays, less myocardial damage, less invasion, and fewer complications compared with conventional open surgery possible for the patients. Successful occlusion of the CAFs at catheterization was reported in $>83-95 \%$ of patients. In the remaining patients, they are to be managed conservatively or with surgery. ${ }^{23}$ Percutaneous CAF closure is reported to yield a high degree of procedural success with low risk of serious complications. ${ }^{7}$ During percutaneous closure of CAF, multiple devices have been used including coils, detachable balloons, covered stents, vascular plugs, atrial septal defect occluder, VSD occluder and PDA occluder. Over the years, there have been a series of transcatheter closure studies in up to 33 patients. Armsby and colleagues reported short-term findings in 33 patients who underwent transcatheter closure. ${ }^{8}$ Follow-up echocardiograms (median: 2.8 years) were obtained in 27 patients. There was no flow in 22 patients and 5 had small residual shunts. None had follow-up angiograms. Recently, Zhu et al. ${ }^{24}$ reported transcatheter closure results of 24 patients. All had clinical follow-up ranging from 3 months to 10 years. No follow-up angiogram was obtained. One patient had a still murmur on examination at 6-month follow-up and subsequent echocardiography revealed residual flow. Not all the CAFs are suitable for percutaneous closure.

Mavroudis et al. ${ }^{25}$ outlined the requirements for satisfactory embolization of a CAF as follows:

(a) the ability to cannulate safely the branch coronary artery that supplies the fistula

(b) absence of large branch vessels that can be inadvertently embolized

(c) the presence of single, narrow restrictive drainage site into the cardiac chamber or vessel, and

(d) the absence of multiple fistulous communications.

Using these criteria, the authors concluded that coil embolization was possible in only $37 \%$ of the fistulas. There are two approaches for percutaneous closure; venous approach and arterial approach. Arterial approach is more suitable for small fistulae that can be closed with coils. While the fistula is large requiring large a device or a plug to close, the venous approach is suitable. Trehan et al. ${ }^{4}$ approached the fistula through the venous approach and closed them with AmplatzerTM devices and while using coils, they went through the arterial route.

The outcome of transcatheter occlusion is as good as that of surgical correction. Patients that are closed by using transcatheter techniques need to be closely followed up for complications such as residual shunts, formation of thrombus, new fistula formation, coronary aneurysma and coronary artery stenosis. Clinical experiences show that the short-, middle- and long-term outcome of transcatheter closure of CAFs has been satisfactory. Residual or recurrent shunts after transcatheter closure have been reported in $10-20 \%$ of patients and these may require further procedures to achieve complete occlusion. ${ }^{24,26}$ A study shows that an incidence of major complications which occurs late after closure of CAFs with transcatheter and surgical interventions is $15 \%$, reported by Valente et al. ${ }^{27}$ Mortality related to surgical closure or transcatheter closure of isolated CAFs is low $(<1 \%)^{20,28}$

In our study, CAF closure was attempted percutaneous occlusion in all the 5 cases \& used three different devices; VAD occluder, PDA Occluder and detachable Cook coil to close the lesions. Among 5 patients, we approached percutaneous CAF closure though venous approach in 4 cases with and only one through arterial approach. The venous approach fistulae were closed with VSD occluder (2) and PDA occluder (2) but the only one arterial approach fistula closed with Cook coil. Just after the device deployment, coronary and aortic angiography performed. At last, the correct position has confirmed and the devices released. Embolization was achieved in all our 5 patients. After, percutaneous closure of CAF, all 5 patients have received heparin $50 \mathrm{IU} / \mathrm{kg}$ body weight 12 hourly for 3 days in our inpatient department and prescribed aspirin $3 \sim 5 \mathrm{mg} / \mathrm{kg}$ body weight for 6 months on discharge. There were no any major complications have found. No death occurred during and after closure.

\section{CONCLUSION}

According to our results and those of previously reported, we are able to say that Percutaneous closer of CAF is very safe and effective. The most of coronary artery fistulae can be closed with percutaneous closure. However, the technique has minimal complications, shorter hospital stay, low morbidity and mortality. But the percutaneous approach is a fairly complicated intervention and requires an experienced operator and interventional specialist with expertise in both coronary arteriography and embolization techniques. In our hospital, there were such specialists who could perform percutaneous embolization.

\section{ACKNOWLWDGMENT}

None.

\section{REFERENCES}

1. Wong $\mathrm{K}$ and Menahem S. Coronary arterial fistulas in childhood. Cardiol Young 2000; 10:15-20. 
2. Baschat AA, Love JC, Stewart PA, Gembruch U and Harman CR. Prenatal diagnosis of ventriculocoronary fistula. Ultrasound Obstet Gynecol 2001; 18:39-43.

3. Gowda RM, Vasavada BC and Khan IA. Coronary Artery fistulas: clinical and therapeutic considerations. Int J Cardiol 2006, 107:7-10.

4. Trehan V, Yusuf J, Mukhopadhyay S, Rangasetty UC, Mehta V, Gupta MD, et al. Transcatther closure of coronary artery fistulas. Indian Heart J 2004; 56:132-139.

5. Tirilomis T, Aleksic I, Busch T, Zenker D, Ruschewski W and Dalichau $\mathrm{H}$. Congenital coronary artery fistula in adults: Surgical treatment and outcome. Inter J Cardiol 2005; 98:57-59.

6. Reidy JF, Sowton E and Ross DN. Transcatheter occlusion of coronary to bronchial anastomosis by detachable balloon combined with coronary angioplasty at same procedure. Brit Heart J 1983; 49:284-287.

7. Collins N, Mehta R, Benson L and Horlick E. Percutaneous coronary artery fistula closure in adults: Technical and procedural aspects. Cathet Cardiovas Interv 2007; 69:872-880.

8. Armsby LR, Keane JF, Sherwood MC, Forbess JM, Perry SB, Lock JE, et al. Management of coronary artery fistulae. Patient selection and results of transcatheter closure. J Am Coll Cardiol 2002; 39:1026-1032.

9. Calafiore PA, Raymond R, Schiavone WA and Rosenkraz ER. Precise evaluation of a complex coronary arteriovenous fistula: The utility of transoesophageal colour Doppler. J Am Soc Echocardiogr 1989; 2:337-341.

10. Giannoccaro PJ, Sochowski RA, Morton BC and Chan KL. Complementary role of transoesophagal echocardiography to coronary angiography in the assessment of coronary artery anomalies. Br Heart J 1993; 70:70-74.

11. Almeida J, Lobo A, Casanova J, Torres JP and Gomes MR. Transesophageal echocardiography on the presurgical and postsurgical evaluation of a coronary arteriovenous fistula. J Am Soc Echocardiogr 1997; 10:224-227.

12. Krishnamoorthy $\mathrm{KM}$ and Rao S. Transesophagial echocardiography for the diagnosis of coronary arteriovenous fistula. Int J Cardiol 2004; 96:281-283.

13. Stevenson JG, Sorenson GK, Stamm SJ, McCloskey JP, Hall DG and Rittenhouse EA. Intraoperative transesophageal echocardiography of coronary artery fistulas. Ann Thorac Surg 1994; $57: 1217-1221$

14. Liberthson RR, Sagar K, Berkoben JP, Weintraub RM and Levine FH. Congenital coronary arteriovenous fistula. Report of 13 patients, review of the literature and delineation of management. Circulation 1979; 59:849-854.
15. Fischer G, Apostolopoulou SC, Rammos S, Schneider MB Bjornstad PG and Kramer HH. Transcatheter closure of coronary arterial fistulas using the new Amplatzer. Vascular Plug Cardiol Young 2007; 17:283-287.

16. Malekahmadi $M$ and Shahmohammadi A. Surgical outcome of coronary artery fistulas repair in children. Pediatr Cardiol 2005; 26:328-330.

17. Cheng TO. Management of coronary artery fistulas: Percutaneous transcatheter embolization versus surgical closure. Catheter Cardiovasc Interv 1999; 46:151-152.

18. Ata $Y$, Turk T, Bicer M, Yalcin M, Ata F and Yavuz F. Coronary arteriovenous fistulas in the adults: Natural history and management strategies. J Cardiothorac Surg 2009; 4:62-66.

19. Biorck $G$ and Crafoord $C$. Arteriovenous aneurysm on the pulmonary artery simulating patent ductus arteriosus botalli. Thorax 1947; 2:65-74.

20. Urrutia-S CO, Falaschi G, Ott DA and Cooley DA. Surgical management of 56 patients with congenital coronary artery fistulas. Ann Thorac Surg 1983; 35:300-307.

21. Lowe JE, Oldham HN and Sabiston DC. Surgical management of congenital coronary artery fistulas. Ann Surg 1981; 194:373-380.

22. Cheung DL, Au WK, Cheung HH, Chiu CS and Lee WT. Coronary artery fistulas: Long-term results of surgical correction. Ann Thorac Surg 2001; 71:190-195.

23. Nakayama Y, Shikawa A, Ayusawa Y, Hosoda S, Muroi K, Yagi M, et al. Surgical repair of complicated coronary arteriovenous fistula and coronary artery aneurysm in an elderly patient after 26 years of conservative therapy. Heart Vessels 2010; 26: 111-116.

24. Zhu XY, Zhang DZ, Han XM, Cui CS, Sheng XT, Wang QG, et al. Transcatheter closure of congenital coronary artery fistulae: Immediate and long-term follow-up results. Clin Cardiol 2009; 32:506-512.

25. Mavroudis C, Backer CL, Rocchini AP, Muster AJ and Gevitz M. Coronary artery fistulas in infants and children: A surgical review and discussion of coil embolization. Ann Thorac Surg 1997; 63:1235-1242.

26. Liang $X$, Zhong-ying $X$, Shi-liang J, Hong Z, Shi-hua Z, Jian L, et al. Transcatheter closure of coronary artery fistula in children. Chin Med J, 2010; 123: 822-826.

27. Valente, AM, Lock JE, Gauvreau K, Huertas ER, Joyce C, Armsby LB, et al. Predictors of Long-Term Adverse Outcomes in Patients with Congenital Coronary Artery Fistulae. Circ Cardiovasc Interv 2010; 3: 134-139.

28. Qureshi, SA. Coronary arterial fistulas. Orphanet J Rare Dis 2006; 1: 1-6. 